\title{
System usability scale evaluation of online banking \\ services: A South African study
}

AUTHORS:

Mathias Mujinga ${ }^{1}$

Mariki M. Eloff ${ }^{2}$

Jan H. Kroeze'

\section{AFFILIATIONS:}

${ }^{1}$ School of Computing, College

of Science, Engineering and

Technology, University of

South Africa, Johannesburg,

South Africa

2Institute for Corporate

Citizenship, University

of South Africa, Pretoria,

South Africa

\section{CORRESPONDENCE TO:}

Mathias Mujinga

\section{EMAIL:}

mujinm@unisa.ac.za

\section{DATES:}

Received: 02 Mar. 2017

Revised: 22 June 2017

Accepted: 03 Nov. 2017

Published: 27 Mar. 2018

\section{KEYWORDS:}

security; privacy; ebanking usability; website usability; South Africa

\section{HOW TO CITE:}

Mujinga M, Eloff MM, Kroeze JH. System usability scale evaluation of online banking service: A South African study. S Afr J Sci. 2018;114(3/4), Art. \#2017-0065, 8 pages. http://dx.doi.org/10.17159/ sajs.2018/20170065

\section{ARTICLE INCLUDES:}

$\times$ Supplementary material

$\times$ Data set

\section{FUNDING:}

National Research Foundation (South Africa)
Online banking is a critical service offered by financial institutions to their clientele to facilitate easier and faster access to financial services and transactions. Banks currently spend huge amounts of money on development and maintenance of websites and backend systems that offer online banking facilities to clients. Here we address the effect of moderating factors on online banking usability assessment in South Africa. Using statistical analysis techniques that included $t$-tests, ANOVA and correlation, we investigated whether there are statistically significant mean differences in system usability scale (SUS) scores based on a variety of moderating factors in South Africa. Findings based on a sample of 540 respondents show that SUS scores differ significantly based on factors such as age, experience and income, whereas factors such as gender, use frequency and employment did not affect the mean SUS scores. Given the individual SUS scores for a variety of users based on different demographics, the financial institutions might improve service usability to target specific user groups and realise their return on investment in digital banking channels. Therefore improving service usability might go a long way in encouraging online banking adoption in South Africa.

\section{Significance:}

- The overall assessment of online banking service by users based on a SUS measurement tool was investigated.

- The effect of moderating variables on the mean SUS scores of different user groups was established.

- An insight into areas of improvement with regard to usability based on demographic information of users is provided.

\section{Introduction}

Online banking is a critical service offered by financial institutions to their clientele to facilitate easier and faster access to financial services and transactions. The service also allows banks to reduce client in-branch visits, thereby combating operational costs. Banks currently spend huge amounts of money on the development and maintenance of websites that offer online banking facilities to clients. To that end, there is a need to address both the security and privacy of the customers' financial and personal information while at the same time providing a system that users can actually use and enjoy. Usability of the channels that provide online banking is significantly important; the main channel is the website user interface, which is usually accessible through a plethora of devices.

This paper addresses the following research question: What is the effect of moderating factors on online banking usability assessment in South Africa? We aim to contribute to the body of knowledge by, firstly, investigating the overall assessment by users of online banking services based on a system usability scale (SUS) measurement tool, and, secondly, establishing the effect of moderating variables on the mean SUS scores of different user groups in the sample.

We investigated the possible effect of service usability as a contributing factor in service adoption based on different population groups. Given the individual SUS scores for a variety of users based on different demographics, the financial institutions might improve service usability to target specific user groups and realise their return on investment in digital banking channels.

\section{Online banking}

Since the late 1990s, the financial landscape has been changing through the use of Internet technologies. Financial institutions are now providing clients with self-service options based on the Internet. These services are optimised for both mobile devices and desktop computers, considering limited bandwidth and the cost of Internet access in less developed communities. The emergence of electronic banking (ebanking) services such as virtual banking, home banking and online banking, which provide various banking activities through digital channels, has revolutionised the industry. ${ }^{2}$

The number of online banking users has been growing throughout the world, as the convenience of using online banking to perform banking transactions throughout the day has an edge over previous delivery channels, mainly a visit to a brick-and-mortar bank branch. Nonetheless, online banking has problems that still need to be addressed to achieve the full benefits of the service, such as usability ${ }^{3}$ and security ${ }^{4}$. Firstly, as much as adoption is increasing, the rate of adoption is not the same across different economies. For instance, the rate of uptake in developed economies is significantly higher than in developing economies. Secondly, there are still security and privacy risks associated with conducting financial activities online that need to be addressed, as cited by previous studies. ${ }^{4}$ 


\section{Online banking in South Africa}

The population of South Africa is approximately 55.9 million $^{5}$, with an adult population of around 42.9 million $^{6}$, based on June 2016 estimates. The country has an Internet penetration rate of $52 \%$, meaning that 28.5 million South Africans are Internet users. ${ }^{7}$ Of the 36.8 million adults, 24.9 million (58\%) have formal bank accounts. ${ }^{6}$ Based on 2014 estimates, 14 million banking adults have Internet access, but only 2.3 million, that is, just more than $9 \%$ of bank account holders, use online banking services ${ }^{8}$, which, in turn, accounts for only $4 \%$ of the total population. This represents a worryingly low level of adoption of the service. In comparison, the online banking adoption rate in the European Union for 2016 was $49 \%$ of the total population, with Norway having the highest rate of $91 \% .{ }^{9}$ Meanwhile, the global uptake of online banking was $28.7 \%$ of the total Internet audience, with the Middle East and Africa at $8.8 \%$, based on the latest available data from $2012 .^{10}$

The majority of South African banks currently provide free-of-charge online banking service in bundled banking packages to encourage clients' uptake of the service. Even individual transactions through digital channels incur no additional charges, as opposed to high fees for conducting the same transactions inside the branch. Regardless of these cost-effective initiatives, the use of online banking in South Africa is still low compared with that in other countries. Internet access is not a significant barrier to online banking adoption in South Africa, as a significant proportion of bank account holders already have access to the Internet, contrary to previous findings by Karjaluoto et al. ${ }^{11}$ This suggests that, in addition to Internet access, there are other factors at play in low online banking adoption.

Online fraud has since been identified as a major deterrent to online banking adoption, with a Kaspersky Lab and B2B International survey ${ }^{12}$ showing that, globally, $64 \%$ of people worry about online banking fraud, and yet only $21 \%$ believe they are a target for cyberattacks. Troublingly, only $60 \%$ use security solutions for any connected devices they own and use online. ${ }^{12}$ With regard to adoption, usability of the user interface of the service might also play a role in inhibiting adoption and continued use.

\section{Usability}

Usability - the reason why users love certain products or services that they use daily - is invisible. As Barnum ${ }^{13}$ puts it: 'When usability is inherent in the products we use, it's invisible. We don't think about it. But we know it's there.' The absence of usability in a product or service brings about frustration; in extreme cases, users decide not to bother using the product or service. Preece et al. ${ }^{14}$ note that most gadgets are engineered to work effectively, while neglecting usability aspects from the users' perspective. The same can be said of most software applications, even more so in information security systems. With this concern in mind, the resulting phenomenon has been the introduction of usability early in the design process, leading Mitnick and Simon ${ }^{15}$ to allude to the notion that attackers are exploiting the human factors neglected by designers to gain access to computer systems.

The subjective nature of what constitutes usability and a wide variety of artefacts that apply the concept of usability have given rise to many definitions of the term 'usability'. One definition of usability that has become a standard is the usability process-oriented approach from ISO $9241-11^{16}$, succinctly summarised by Bevan et al. ${ }^{17}$ as 'the extent to which a product can be used by specified users to achieve specified goals with effectiveness, efficiency, and satisfaction in a specified context of use'. The definition highlights three key aspects: specific users, specified goals and a specified context of use. As scholars and practitioners have become familiar with numerous aspects of usability, it has become apparent that usability is not a one-dimensional property of a user interface, but that it incorporates attributes such as learnability, efficiency, memorability, errors and satisfaction. ${ }^{18}$

\section{Usability goals}

There are numerous usability goals suggested by scholars, and some of them are prescribed for specific information technology systems and services. Rubin and Chisnell ${ }^{19}$ argue that what makes a system usable is the 'absence of frustration' while interacting with it. The authors go on to state that when a product or service is truly usable, 'the user can do what he or she wants to do the way he or she expects to be able to do it, without hindrance, hesitation, or questions'. ${ }^{19}$ Figure 1 illustrates the position of usability in a wider system acceptability context.

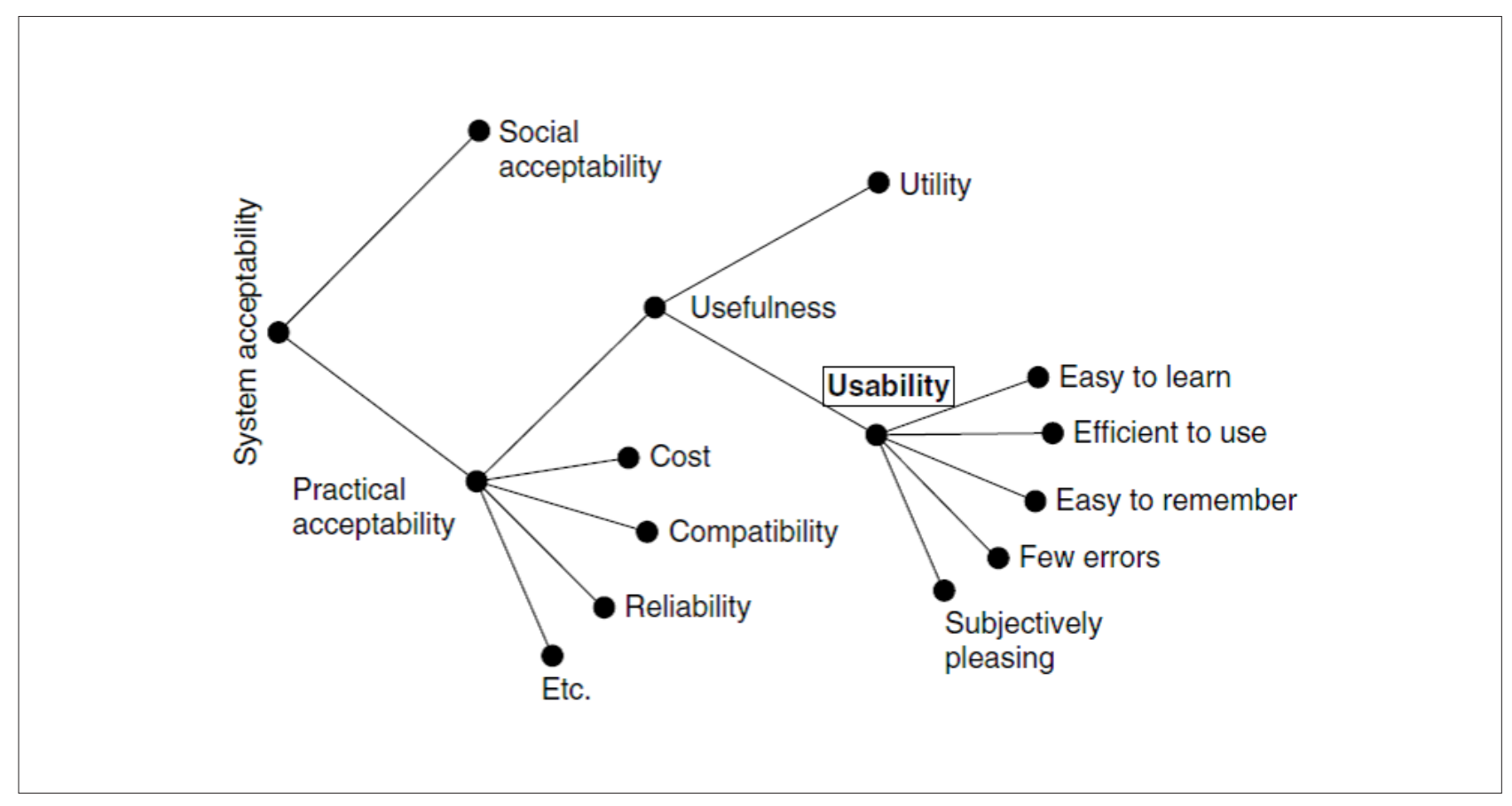

Source: Nielsen ${ }^{18}$

Figure 1: System acceptability attributes. 
Social acceptability and practical acceptability form part of system acceptability. Practical acceptability also considers aspects such as reliability, compatibility, cost and usefulness, to name but a few. Usefulness is explained in terms of utility and usability, where utility assesses whether the system provides the intended functionality while usability considers how well users can use the system functionality. ${ }^{18}$ Figure 1 lists easy to learn, efficient to use, easy to remember, few errors and subjectively pleasing as the main usability goals. It is important to note that a product or service has to first be useful in completing a specific task before looking at how usable it is to the user.

\section{Website usability}

With regard to websites, usability is an important aspect in the design of successful online portals. To quote Nielsen ${ }^{20}$, one of the main web usability authors: 'Usability rules the Web. Simply stated, if the customer can't find a product, then he or she will not buy it.' The same sentiment applies to services offered through online channels, including online banking. If users cannot find online banking functions provided by the website, chances are high that they will simply not use the website and will visit the branch or make a telephone call instead. Given huge investments by financial institutions in digital channels, it is important to use any means possible to help users migrate to online banking, and making online banking websites and interfaces usable is a major step in the right direction.

Website usability is critical in attracting new visitors and has a direct influence on customer satisfaction. ${ }^{21}$ Users are unlikely to revisit a website that exhibits poor usability, and hence, customer loyalty to a website is significantly influenced by website usability. ${ }^{22}$ Given the potential risk of financial loss, services such as online banking need to meet both usability and security goals. Measuring usability is often difficult, as usability of a product or service is highly subjective. As such, there are quite a number of ways to measure usability. One such measurement tool is the standardised SUS developed by Brooke ${ }^{23}$. We used the SUS tool to measure the usability of online banking services in South Africa. We report on the results of survey data collected from online banking users, based on 10 survey items that constitute the SUS measurement tool (see Appendix).

\section{Related work}

A number of studies have been conducted on factors affecting online banking adoption in individual economies across developed and developing economies. Most of these studies have been limited to identifying online banking benefits and inhibitors. Numerous factors such as service usefulness, ease of use, security, usability, lack of Internet infrastructure and Internet access costs have been brought to the fore. Apart from single-case studies, some scholars have performed a systematic analysis of studies on the topic of online banking adoption across cases to identify significant factors. The following paragraphs outline some of the recent studies in this area.

In India, Sikdar et al. ${ }^{24}$ identified trust, usage constraint, ease of use, accessibility and intention to use as significant factors determining Internet banking adoption, while accessibility, usage constraints and intention to use displayed a strong and significant relationship with overall customer satisfaction. Szopiński ${ }^{25}$ identified factors that determined the adoption of online banking in Poland as mainly the use of the Internet, taking advantage of other banking products and trust in commercial banks.

In the South African context, Brown and Molla ${ }^{26}$ investigated the determinants of Internet and cellphone banking in 2005. Their findings identified a significant difference between factors affecting Internet and cellphone banking. It is important to note that the study was done during the initial stages of both Internet and cellphone banking in South Africa and that Internet and cellphone network coverage was not countrywide; in addition, the cost of data was exorbitant. Given the current overlap of online banking users accessing the service through multiple devices, such as mobile and desktop computers, no significant difference exists in adoption factors of the service between mobile or non-mobile devices. Since then, the technology landscape for both technologies has significantly changed.

A more recent study by Ramavhona and Mokwena ${ }^{4}$ highlighted the lack of online banking adoption in rural South Africa, irrespective of efforts by financial institutions to promote the service. The study identified perceived security risk and lack of Internet infrastructure as the main inhibitors of adoption. Although security risk is still a concern countrywide, lack of Internet infrastructure is not necessarily a factor in urban areas. The authors cited the complexity of using the service in terms of lack of userfriendliness as a contributing factor in lack of adoption. In our previous study, we identified security as the main concern among online banking users, while service convenience was cited as the main attraction among current service users, mainly in Gauteng. ${ }^{27}$

Hanafizadeh et al. ${ }^{28}$ conducted a systematic review of 165 Internet banking adoption studies between 1999 and 2012 and reported on a wide range of types of studies. The three types included studies that sought a description of the phenomenon, interplay between identified factors, and high-level comparison across populations, channels and methods. Another systematic review of 25265 cases of online banking adoption by Montazemi and Qahri-Saremi ${ }^{29}$ identified factors that had differing importance based on consumers' pre-adoption and post-adoption of the service. The findings reinforced the significance of original technology acceptance model constructs of perceived usefulness and perceived ease of use in online banking adoption. The authors also highlighted the significant influence of trust in online banking services as well as in the physical bank on the intention to use the service.

Besides determinants of online banking adoption, there is limited work on the relationship between usability and adoption of the service. Tassabehij and Kamala et al. ${ }^{30}$ performed a SUS evaluation of an online banking biometric authentication system prototype. Their findings found the biometric system usable based on respondents' SUS scoring, with no major differences between gender and age groups. Although the findings were favourable in a prototype system, these cannot be generalised to a commercially developed system, as there are still major usability and privacy issues with biometric systems. Krol et al. ${ }^{3}$ reported on the usability of a two-factor authentication mechanism for online banking that used hardware tokens. The respondents from the study highlighted a preference for biometric authentication because of the high degree of mental and physical workload and usability issues of hardware tokens.

Although users prefer biometric authentication systems for online banking and other online applications, there are still significant usability problems with biometric technology. For instance, Bhagavatula et al. ${ }^{31}$ identified system reliability issues in popular smartphone devices' biometric technology. In general, biometric authentication methods are rarely used in online banking systems as a result of high cost and difficulty of use for people living with disabilities. ${ }^{32} \mathrm{~A}$ study by Belanche et al. ${ }^{21}$ showed that website usability affected satisfaction, which in turn had an impact on intention to use. Their findings concluded that usability did not necessarily affect intention to use, but had an indirect effect through consumer satisfaction.

This paper reports on a SUS assessment of the current online banking system in South Africa as provided by major retail banks to customers. The work provides a first insight into service usability, as no other such studies have been conducted in South Africa. Given the low adoption rate of online banking services in South Africa, we investigated the possible effect of the usability of the service on adoption decisions.

\section{Research methodology}

The study follows a positivist philosophy that is mainly associated with quantitative research that is focused on collecting quantitative data for theory testing to increase the predictive nature of understanding the phenomenon under investigation. ${ }^{33}$ The study uses a deductive research approach that involves hypothesis testing evaluated through empirical observations. ${ }^{34}$ Using a survey research method, an online questionnaire was distributed to online banking users, and 540 valid and usable responses were filled in by respondents from across all nine provinces of South Africa. The majority of responses came from clients of South 
Africa's five major banks (ABSA, Capitec, FNB, Nedbank and Standard Bank). The respondents were current users of online banking services who evaluated the service based on the 10-item SUS measurement tool.

\section{System usability scale}

SUS is intended to provide an easy and quick subjective measure of usability. SUS is a standardised, inexpensive and reliable low-cost usability scale for system or product usability assessment. ${ }^{35}$ SUS provides a quick and easy measurement of a user's subjective rating of a product or service usability. Brooke ${ }^{23}$ developed SUS as a 10-statement measurement tool that uses a Likert scale for scoring SUS statements. An empirical systematic evaluation of SUS studies of over 10 years found the tool to be useful as a quick and easy method of measuring system usability. ${ }^{36}$ We used a five-point Likert scale to measure the degree of agreement with SUS statements, from strongly disagree to strongly agree, scored from 1 to 5 , respectively.

The SUS statements were modified to reflect online banking as the system under evaluation. A single SUS score indicates a composite measure of the system's overall usability as evaluated by the user, but individual item scores are meaningless on their own. ${ }^{23}$ Hence, a variety of ratings was developed to interpret SUS scores and rate the usability of a system. The range of individual SUS item scores was from 0 to 4 , covering the five-point Likert scale, as shown in Table 1.

Table 1: System usability scale scoring

\begin{tabular}{c|c|c|c|c|c}
\hline \hline $\begin{array}{c}\text { Likert scale } \\
\text { degree }\end{array}$ & $\begin{array}{c}\text { Strongly } \\
\text { disagree }\end{array}$ & Disagree & Neutral & Agree & $\begin{array}{c}\text { Strongly } \\
\text { agree }\end{array}$ \\
\hline Scale position & 1 & 2 & 3 & 4 & 5 \\
\hline Item score & 0 & 1 & 2 & 3 & 4 \\
\hline
\end{tabular}

SUS questionnaire items consisted of alternating five positive (numbered 1, 3, 5, 7 and 9) and five negative (numbered 2, 4, 6, 8 and 10) statements. The alternation between positive and negative statements was deliberate to avoid response biases. ${ }^{37}$ Positive statements were scored by subtracting 1 from the Likert scale position, while negative statements were scored by subtracting the scale position from 5 . Finally, the overall SUS score was obtained by multiplying the sum of all individual scores by 2.5 to obtain a score in the range $0-100 .{ }^{37}$ The mean SUS score of all valid system evaluation responses gave an indication of the overall system usability. Bangor et al..$^{35}$ developed usability ratings based on mean SUS scores, as indicated in Figure 2.

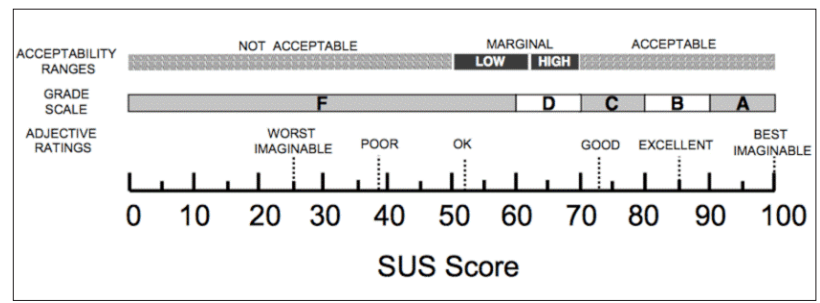

Source: Bangor et al. ${ }^{35}$

Figure 2: Comparison of mean system usability scale (SUS) score ratings.

The figure shows three ratings, namely, acceptability ranges, grade scale and adjective ratings, all based on SUS score ranges. A SUS score below 50 indicates poor usability (not acceptable) of the artefact under investigation, while a score between 50 and 70 indicates marginal acceptability, and a score above 70 indicates an acceptable (good, excellent and best imaginable or better) level of usability. ${ }^{35}$

\section{Ethical considerations}

This study was reviewed and approved by the Research Ethics Committee of the College of Science, Engineering and Technology at the University of South Africa. The respondents were informed about the voluntary nature of participation, with the right to withdraw at any time, before submitting an anonymous online survey. The online survey provided a compulsory tick box for giving consent to participate. The results do not mention the bank names to avoid any undue prejudice, although these data were collected.

\section{Empirical results}

The collected data were prepared for analysis using IBM SPSS Statistics 24. The paper provides descriptive statistics of frequencies performed on the data, followed by more advanced techniques on SUS scores that included $t$-testing, analyses of variance (ANOVA) and correlation analyses.

\section{Descriptive statistics}

Table 2 shows the frequency statistics and mean SUS scores for different groups of respondents as extracted from the IBM SPSS statistical package. More than half of the 540 respondents $(58.1 \%)$ are male, while $41.9 \%$ are female. Furthermore, the results indicated that a plurality of respondents (36.1\%) are in the 30-39 year age group, followed by those aged 20-29 years (with 22.6\%).

The majority of respondents $(66.5 \%)$ had 5 years' or more experience using online banking, while $48.5 \%$ of them had more than 7 years' experience. A significant proportion of users used the service once a week (with $39.6 \%$ ), followed by daily users at $34.3 \%$. Further analysis revealed that the majority (83.8\%) of 185 daily users mainly used a mobile device to access online banking, while almost half (49.7\%) used all three devices (mobile devices, laptops and personal computers), and only $23.2 \%$ used a single device.

Mobile devices were the device most frequently used $(73.7 \%)$ to access online banking, followed by personal computers $(72.2 \%)$ and laptops (61.3\%); $70 \%$ of respondents used more than one device to access online banking, while $37.4 \%$ used all three devices, and $30 \%$ used a single device.

These findings support the logical assumptions that mobile devices facilitate frequent access and that the more devices users have at their disposal, the more frequently they will use the service.

\section{Mean SUS scores rating}

With regard to grade scale and adjective rating, $11 \%$ of respondents scored their online banking as grade A, with SUS scores between 90 and $100,25 \%$ rated it as excellent (grade B), and $34 \%$ considered the service to be good (grade C). With an overall mean SUS score of 73.8 , the majority of respondents $(70 \%)$ rated their online banking service as having a 'good' subjective rating and an 'acceptable' acceptability range. An analysis of the extreme low and high SUS scores showed that only 9 $(2 \%)$ users considered the service to be 'best imaginable', with a perfect 100 SUS score, while 67 (12\%) users gave SUS scores below 60 that resulted in a grade $F$, with $7 \%$ of users rating the service either as 'poor' or 'worst imaginable'. The extreme scores and the overall average rating show that there is significant room for improvement and a critical need to address usability issues of online banking in South Africa.

\section{Inferential statistics}

We performed a set of inferential statistical analyses to investigate the differences in mean SUS scores based on a set of study propositions. The overall null hypothesis for this study contended that there was no significant difference between mean SUS scores across individual moderating factors, including groups within these factors. To investigate this hypothesis, we used a series of analysis techniques, namely $t$-tests, ANOVAs and correlations, in order to make a decision on whether to reject or accept the null hypothesis. 
Table 2: Frequencies and mean system usability scale (SUS) scores, $n=540$

\begin{tabular}{|c|c|c|c|c|c|}
\hline Factor & Category & Frequency & Percentage & $\begin{array}{l}\text { Cumulative } \\
\text { percentage }\end{array}$ & $\begin{array}{l}\text { SUS } \\
\text { score }\end{array}$ \\
\hline \multirow{2}{*}{ Gender } & Male & 314 & 58.1 & 58.1 & 73 \\
\hline & Female & 226 & 41.9 & 100.0 & 74 \\
\hline \multirow{5}{*}{ Age } & Below 20 years & 26 & 4.8 & 4.8 & 65 \\
\hline & 20-29 years & 122 & 22.6 & 27.4 & 73 \\
\hline & 30-39 years & 195 & 36.1 & 63.5 & 75 \\
\hline & 40-49 years & 88 & 16.3 & 79.8 & 74 \\
\hline & $\begin{array}{l}50 \text { years or } \\
\text { older }\end{array}$ & 109 & 20.2 & 100.0 & 74 \\
\hline \multirow{5}{*}{ Experience } & Below 1 year & 39 & 7.2 & 7.2 & 76 \\
\hline & $1-2$ years & 46 & 8.5 & 15.7 & 74 \\
\hline & 3-4 years & 96 & 17.8 & 33.5 & 74 \\
\hline & $5-6$ years & 97 & 18.0 & 51.5 & 67 \\
\hline & $\begin{array}{l}7 \text { years and } \\
\text { above }\end{array}$ & 262 & 48.5 & 100.0 & 77 \\
\hline \multirow{6}{*}{$\begin{array}{l}\text { Income } \\
(\mathrm{ZAR})\end{array}$} & $\begin{array}{l}\text { Less than } \\
10000\end{array}$ & 73 & 13.5 & 13.5 & 67 \\
\hline & $10000-19999$ & 68 & 12.6 & 26.1 & 71 \\
\hline & $20000-29999$ & 102 & 18.9 & 45.0 & 74 \\
\hline & $30000-39999$ & 130 & 24.1 & 69.1 & 77 \\
\hline & $40000-49999$ & 46 & 8.5 & 77.6 & 77 \\
\hline & 50000 or more & 121 & 22.4 & 100.0 & 75 \\
\hline \multirow{5}{*}{$\begin{array}{l}\text { Use } \\
\text { frequency }\end{array}$} & Every day & 185 & 34.3 & 34.3 & 64 \\
\hline & Once a week & 214 & 39.6 & 73.9 & 70 \\
\hline & $\begin{array}{l}\text { Once in } 2 \\
\text { weeks }\end{array}$ & 71 & 13.2 & 87.1 & 72 \\
\hline & Once a month & 65 & 12.0 & 99.1 & 74 \\
\hline & Other & 5 & 0.9 & 100.0 & 77 \\
\hline \multirow{5}{*}{ Employment } & Employed & 431 & 79.8 & 79.8 & 75 \\
\hline & Self-employed & 53 & 9.8 & 89.6 & 71 \\
\hline & Unemployed & 28 & 5.2 & 94.8 & 63 \\
\hline & Retired & 14 & 2.6 & 97.4 & 71 \\
\hline & Other & 14 & 2.6 & 100.0 & 71 \\
\hline \multirow[b]{2}{*}{ Device } & Any one device & 134 & 24.8 & 24.8 & 72 \\
\hline & $\begin{array}{l}\text { Two or more } \\
\text { devices }\end{array}$ & 406 & 75.2 & 100.0 & 74 \\
\hline
\end{tabular}

Independent samples $t$-test

We performed $t$-tests on mean SUS scores as opposed to the actual Likert scale scores, as these are meaningless before conversion. Independent samples $t$-tests work with variables that have, at most, two categories; in this study, only gender and device satisfied this criterion. This allowed the testing of hypotheses that compared two groups in the population for a decision on whether to accept or reject the null hypothesis.

\section{Gender}

The results of two independent samples $t$-tests, Levene's test for equality of variances and the $t$-test for equality of means, are illustrated in Table 3. The results showed that the $p$-value of Levene's test was 0.817 , which was greater than the threshold value of 0.05 , so we accepted the null hypothesis that there was no significant difference between the means of Levene's test and concluded that the variance in SUS scores for male and female respondents was equal; hence, the difference was statistically insignificant, which meant that we had to consider the output of equal variance assumed in order to test for equality of means.

\section{Device}

Table 4 shows independent samples $t$-tests performed to compare mean SUS scores between users who used 'any one device' and those who used 'two or more devices'. The mean SUS scores difference of -2.5117 shows that there was a significant difference, but further tests were necessary to investigate if the difference was statistically significant.

\section{One-way ANOVA}

We performed one-way ANOVAs for the categorical moderating factors, to compare the means of two or more independent groups in order to determine whether there was statistical evidence that the associated population means were significantly different. One-way ANOVA and $t$-testing are equivalent tests that test mean differences between groups; however one-way ANOVA goes a step further to provide the capability to analyse more than two groups, while $t$-testing compares only two groups. ${ }^{38}$ The test statistic for a one-way ANOVA is denoted as $F$. Table 5 summarises the oneway ANOVA $F$ - and $p$-values for moderating effects on mean SUS scores (between groups values), including post-hoc tests for group comparisons. The factors are ordered in order of statistical significance.

All five age groups exhibited statistically significant differences, with $p$-values ranging between 0.001 and $0.022(p<0.05)$ with 'between groups' values of $(F=3.925, p=0.004)$. This finding led to the conclusion that SUS scores significantly differed based on online banking users' age, with older users scoring relatively higher than younger users. This trend was also supported by the plot graph, although the 40-49 years age group scored a little lower than the preceding 30-39 years age group.

Statistically significant differences in mean SUS scores were shown for experience among all groups, except 'less than 12 months' versus '1-2 years'. This finding was supported by the plot chart that showed SUS scores increasing as experience increased. It follows that more experienced users were more likely than novice users to score a system highly in usability evaluation assessments. Therefore, our findings are in line with previous studies which concluded that as users became familiar with an interface, they considered it more usable because they could locate functions more easily. ${ }^{39}$ We can conclude that website and interface usability improve with increased familiarity, as users become less and less frustrated with the system because they can locate and use functions more quickly and easily with time.

When contrasting income groups against the 'less than ZAR10 000' group, all comparisons were statistically significant, except the one against the 'ZAR20 000-ZAR29 999' group. These findings suggested that users with a higher income tended to have higher perceptions of the usability of online banking service compared to their lower-income counterparts.

Although one-way ANOVA mean SUS scores between groups for 'use frequency' showed a statistically significant difference with $p<0.05$, only one group comparison between the 'daily' and 'once a month' groups was found to be statistically significant, with $p=0.001$. The same applied to 'experience', with only one group comparison between 'unemployed' and 'employed' being statistically significant with $p=0.001$. Although data were collected for additional moderating factors such as education, ethnicity, language, province and bank, these were excluded from the analysis because the differences in means for SUS scores were statistically insignificant among the respective group comparisons ( $p>0.05$ in one-way ANOVA). Therefore, for these factors we accept the null hypothesis and conclude that there is no significant difference in mean SUS scores between groups. 
Table 3: $\quad$ Independent samples test: Gender

\begin{tabular}{|c|c|c|c|c|c|c|c|c|c|c|}
\hline & & \multicolumn{2}{|c|}{$\begin{array}{l}\text { Levene's test for } \\
\text { equality of variances }\end{array}$} & \multicolumn{7}{|c|}{$t$-test for equality of means } \\
\hline & & \multirow{2}{*}{$\mathbf{F}$} & \multirow{2}{*}{ Significance } & \multirow{2}{*}{$t$} & \multirow{2}{*}{ d.f. } & \multirow{2}{*}{$\begin{array}{l}\text { Significance } \\
\text { (two-tailed) }\end{array}$} & \multirow{2}{*}{$\begin{array}{c}\text { Mean } \\
\text { difference }\end{array}$} & \multirow{2}{*}{$\begin{array}{l}\text { Standard } \\
\text { error } \\
\text { difference }\end{array}$} & \multicolumn{2}{|c|}{$\begin{array}{l}95 \% \text { confidence interval } \\
\text { of the difference }\end{array}$} \\
\hline & & & & & & & & & Lower & Upper \\
\hline \multirow{2}{*}{$\begin{array}{l}\text { System usability } \\
\text { scale (SUS) scores }\end{array}$} & Equal variances assumed & 0.054 & 0.817 & -0.948 & 538 & 0.343 & -1.063 & 1.121 & -3.266 & 1.139 \\
\hline & Equal variances not assumed & & & -0.948 & 484.3 & 0.344 & -1.063 & 1.122 & -3.267 & 1.141 \\
\hline
\end{tabular}

The test for equality of means provided the actual independent samples $\mathrm{t}$-test. The mean difference in SUS scores between genders of 1.063 at 0.05 level ( $\mathrm{p}=0.343)$ meant that we could accept the null hypothesis that there was no significant difference in SUS scores based on gender.

Table 4: Independent samples test: Device

\begin{tabular}{|c|c|c|c|c|c|c|c|c|c|c|}
\hline & & \multicolumn{2}{|c|}{$\begin{array}{l}\text { Levene's test for } \\
\text { equality of variances }\end{array}$} & \multicolumn{7}{|c|}{$t$-test for equality of means } \\
\hline & & \multirow{2}{*}{$\mathbf{F}$} & \multirow{2}{*}{ Significance } & \multirow[t]{2}{*}{$t$} & \multirow{2}{*}{ d.f. } & \multirow{2}{*}{$\begin{array}{l}\text { Significance } \\
\text { (two-tailed) }\end{array}$} & \multirow{2}{*}{$\begin{array}{c}\text { Mean } \\
\text { difference }\end{array}$} & \multirow{2}{*}{$\begin{array}{l}\text { Standard } \\
\text { error } \\
\text { difference }\end{array}$} & \multicolumn{2}{|c|}{$\begin{array}{l}95 \% \text { confidence interval } \\
\text { of the difference }\end{array}$} \\
\hline & & & & & & & & & Lower & Upper \\
\hline \multirow{2}{*}{$\begin{array}{l}\text { System usability } \\
\text { scale (SUS) scores }\end{array}$} & Equal variances assumed & 4.627 & 0.032 & -1.967 & 538 & 0.050 & -2.5117 & 1.277 & -5.020 & -0.003 \\
\hline & $\begin{array}{l}\text { Equal variances not } \\
\text { assumed }\end{array}$ & & & -1.817 & 200.8 & 0.071 & -2.5117 & 1.383 & 5.238 & 0.2148 \\
\hline
\end{tabular}

We test the null hypothesis that the mean difference in SUS scores is insignificant for users using one device and those using at least two devices. Levene's test for equality of variances has $\mathrm{p}=0.032$, which is lower than the threshold value of 0.05 . Therefore, we reject the null hypothesis of Levene's test and conclude that the variance in SUS scores between the two groups is significant, and as a consequence we consider the row that assumes unequal variances. The output for equal variance not assumed indicates that the difference in means is statistically insignificant at $\mathrm{p}=0.071$ ( $\mathrm{t}=-1.817, \mathrm{p}>0.05)$.

Table 5: $\quad$ One-way ANOVA of system usability scale (SUS) scores versus moderating factors

\begin{tabular}{l|c|c|c|c|}
\hline \multicolumn{1}{c|}{ Factor } & d.f. & F & Signfiicance & \multicolumn{2}{c}{ Post-hoc tests (multiple comparisons) } \\
\hline Age & 4 & 3.925 & 0.004 & All \\
\hline Experience & 4 & 10.338 & 0.000 & Less than 1 year versus 1-2 years \\
\hline Income & 5 & 7.524 & 0.000 & Less than ZAR10 000 versus ZAR10 000-ZAR19 999 \\
\hline Use frequency & 4 & 5.991 & 0.000 & Daily versus once a month \\
\hline Employment & 4 & 7.497 & 0.05 & $p>0.05$ \\
\hline
\end{tabular}

\section{Correlation}

Correlation analysis was implemented to specify the strength and direction of relationships between the dependent variable SUS scores and independent categorical variables. A correlation coefficient $(r)$ indicates the degree of relation among two or more variables, and it ranges between -1.00 and +1.00 (inclusive). A value of +1.00 means that there is a direct (positive) relation between the two variables, meaning that as one variable increases, the other increases..$^{40}$ Graphically, this is shown by a positive gradient. A value of -1.00 indicates an inverse (negative) relation. When there is no correlation between variables, the coefficient value is 0 . Table 6 shows the results of the correlation analysis performed; interpreted findings are highlighted in bold font.
According to Pallant ${ }^{41}$, a relationship that has a Pearson correlation value (magnitude) below 0.3 is weak, while a Pearson correlation value between 0.3 and 0.5 is termed moderate, and anything with a magnitude between 0.5 and 1 is termed strong. Table 6 indicates that the relationships between SUS scores and the categorical moderating factors income, experience, use frequency, and employment were significant at the 0.01 level (two-tailed), while age was statistically significant at the 0.05 level. Although there is a correlation between these moderating factors and SUS scores, the value of $r< \pm 0.3$ indicates weak relationships. ${ }^{41}$ Income and experience had a positive weak relationship with SUS scores, while use frequency and employment exhibited a negative weak relationship with SUS scores. Additionally, the correlations between 'income versus age', 'experience versus age', and 'experience versus income' showed positive, moderately strong relationships at $p<0.01$. 
Table 6: $\quad$ Correlation analysis between system usability scale (SUS) scores and categorical variables

\begin{tabular}{|c|c|c|c|c|c|c|c|}
\hline & & SUS scores & Age & Experience & Income & Use frequency & Employment \\
\hline \multirow{2}{*}{ SUS scores } & Pearson correlation & 1 & & & & & \\
\hline & Significance (two-tailed) & & & & & & \\
\hline \multirow{2}{*}{ Age } & Pearson correlation & $0.090^{\star}$ & 1 & & & & \\
\hline & Significance (two-tailed) & 0.036 & & & & & \\
\hline \multirow{2}{*}{ Experience } & Pearson correlation & $0.259^{\star \star}$ & $0.464^{\star \star}$ & 1 & & & \\
\hline & Significance (two-tailed) & 0.000 & 0.000 & & & & \\
\hline \multirow{2}{*}{ Income } & Pearson correlation & $0.192^{\star *}$ & $0.495^{\star \star}$ & $0.556^{\star \star}$ & 1 & & \\
\hline & Significance (two-tailed) & 0.000 & 0.000 & 0.000 & & & \\
\hline \multirow{2}{*}{ Use frequency } & Pearson correlation & $-0.176^{\star \star}$ & -0.017 & $-0.196^{\star \star}$ & $-0.212^{* *}$ & 1 & \\
\hline & Significance (two-tailed) & 0.000 & 0.699 & 0.000 & 0.000 & & \\
\hline \multirow{2}{*}{ Employment } & Pearson correlation & $-0.167^{\star \star}$ & $-0.119^{\star \star}$ & $-0.365^{\star \star}$ & $-0.382^{* \star}$ & $0.189^{\star \star}$ & 1 \\
\hline & Significance (two-tailed) & 0.000 & 0.006 & 0.000 & 0.000 & 0.000 & \\
\hline
\end{tabular}

Correlation is significant at the ${ }^{*} 0.05$ level or the ${ }^{* *} 0.01$ level (two-tailed)

Interpreted findings are highlighted in bold font.

\section{Conclusion}

We report on the first SUS assessment of online banking services in South Africa. With a sample size of 540 , the results of the statistical analyses prove the findings are statistically significant to be generalised to the population at large. The moderating factors analysed in the study had varying effects on mean SUS scores. Using independent samples $t$-tests, gender did not have a statistically significant influence on mean SUS scores while device had statistical significance based on Levene's test but not with $t$-test equality of means. ANOVA results showed statistically significant mean differences for all age group comparisons. While the comparisons among income and experience groups were statistically significant for most groups, only one group comparison from each variable was found to be statistically insignificant. The comparison among use frequency and employment groups found that most group comparisons had mean differences that were statistically insignificant, with both variables having only one group comparison that was statistically significant.

The study highlights that, generally, younger users rated online banking service in South Africa poorly compared to older users. This can partly be explained by a lack of experience and familiarity with the user interface, as older and higher-income users tended to use the service more frequently. We also assume that with the prevalence of social media applications, younger users might be rating online banking against applications with better usability and user experience. This paper contributes to the development of the literature with regard to the usability of online banking services and adoption decisions in the context of the South African financial environment. Given the diverse group of online banking users and the one-size-fits-all service approach, insight into the usability evaluation of the service by users is critical in improving the service and making sure that it is used effectively to maintain a secure online banking environment.

The paper is limited to the usability assessment based on the SUS measurement tool, which comprises 10 items to measure system usability. Therefore, a more comprehensive usability assessment of online banking can be obtained by using an in-depth survey tool that evaluates individual usability principles, thereby yielding a more insightful analysis of the phenomenon. Another limitation is the fact that perceptions were solicited from current users of the service; it would be helpful to get the views of non-users of the service on their reasons for non-adoption. There is a need to conduct an in-depth investigation to identify factors that lead to younger users scoring usability poorly. This can be achieved by conducting an indepth usability evaluation that specifically investigates a variety of usability principles identified in the literature. Financial institutions can then address these specific factors to improve overall service usability, which might improve overall service adoption.

\section{Acknowledgements}

This article is based on doctoral research by Mathias Mujinga. The research was supported in part by the National Research Foundation (NRF) of South Africa. The University of South Africa (UNISA) is acknowledged for granting a period of research and development leave to the first and third authors during which time the article was completed. Any opinion, finding, conclusion and recommendation expressed is that of the authors, and neither the NRF nor UNISA accepts any liability in this regard.

\section{Authors' contributions}

M.M. was responsible for the conceptualisation, methodology, data collection, data analysis, writing the initial draft, and writing revisions. M.M.E. was responsible for validation, critically reviewing the writing and revisions, student supervision and project leadership. J.H.K. was responsible for validation, critically reviewing the writing and revisions, and student supervision.

\section{References}

1. Gkoutzinis AA. Internet banking and the law in Europe: Regulation, financial integration and electronic commerce. London: Cambridge University Press: 2006. https://doi.org/10.1017/cb09780511494703.003

2. Turban E, Rainer RK, Potter RE. Introduction to information technology. 3rd ed. Hoboken, NJ: John Wiley and Sons; 2005.

3. Krol K, Philippou E, De Cristofaro E, Sasse MA. "They brought in the horrible key ring thing!": Analysing the usability of two-factor authentication in UK online banking. In: Proceedings of USEC 2015: NDSS Workshop on Usable Security; 2015 February 08-11; San Diego, CA, USA. Reston, VA: Internet Society; 2015. p. 1-10.

4. Ramavhona TC, Mokwena S. Factors influencing Internet banking adoption in South African rural areas. S Afr J Inf Manage. 2016;18(2):1-8. https://doi. org/10.4102/sajim.v18i2.642

5. Stats SA. Mid-year estimates 2016 [document on the Internet]. c2016 [cited 2017 Feb 14]. Available from: http://www.statssa.gov.za/?p=8176

6. FinMark Trust. FinScope South Africa 2016 [document on the Internet]. c2016 [cited 2017 Nov 06]. Available from: https://www.finmark.org.za/ results-from-finscope-south-africa-2016-survey-on-financial-inclusion/

7. Internet Live Stats. South Africa Internet users [document on the Internet] c2017 [cited 2017 Nov 06]. Available from: http://www.internetlivestats.com/ internet-users/south-africa/ 
8. Van Zyl G. FNB rated SA's 'top internet banking provider'. Fin24. 2015 May 07;Tech News [cited 2017 Nov 06]. Available from: http://www.fin24.com/ Tech/News/FNB-rated-SAs-top-internet-banking-provider-20150507.

9. Statista. Online banking penetration in selected European markets in 2016 [homepage on the Internet]. c2017 [cited 2017 Nov 06]. Available from: https://www.statista.com/statistics/222286/online-banking-penetration-inleading-european-countries/

10. Statista. Global online banking penetration in April 2012, by region [homepage on the Internet]. c2012 [cited 2017 Nov 06]. Available from: https://www. statista.com/statistics/233284/development-of-global-online-bankingpenetration/

11. Karjaluoto $\mathrm{H}$, Mattila M, Pento T. Electronic banking in Finland: Consumer beliefs and reactions to a new delivery channel. Journal of Financial Services Marketing. 2002;6(4):346-361. https://doi.org/10.1057/palgrave. fsm.4770064

12. Kaspersky $L a b$ and $B 2 B$ International. Consumer security risks survey 2016 : Connected but not protected. USA: Kaspersky Lab and B2B International; 2016.

13. Barnum CM. Usability testing essentials: Ready, set... test! Burlington, MA: Morgan Kaufmann; 2011. https://doi.org/10.1109/tpc.2011.2159642

14. Preece J, Rogers $Y$, Sharp H. Interaction design: Beyond human-computer interaction. 4th ed. Chichester: John Wiley \& Sons; 2015.

15. Mitnick KD, Simon WL. The art of deception: Controlling the human element of security. Indianapolis, IN: Wiley Publishing; 2002.

16. ISO 9241-11. Ergonomic requirements for office work with visual display terminals (VDTs): Guidance on usability. Geneva: International Organization for Standardization; 1998.

17. Bevan N, Carter J, Harker S. ISO 9241-11 revised: What have we learnt about usability since 1998? In: Kurosu M, editor. Human-computer interaction: Design and evaluation. Los Angeles, CA: Springer; 2015. p. 143-151. https:// doi.org/10.1007/978-3-319-20901-2_13

18. Nielsen J. What is usability? In: Wilson $C$, editor. User experience re-mastered: Your guide to getting the right design. Burlington, MA: Morgan Kaufmann; 2010. p. 3-22. https://doi.org/10.1016/B978-0-12-375114-0.00004-9

19. Rubin J, Chisnell D. Handbook of usability testing: How to plan, design and conduct effective tests. 2nd ed. Indianapolis, IN: John Wiley \& Sons; 2008.

20. Nielsen J. Designing web usability: The practice of simplicity. Berkeley, CA: New Riders Publishing; 2000.

21. Belanche D, Casaló LV, Guinalíu M. Website usability, consumer satisfaction and the intention to use a website: The moderating effect of perceived risk. Journal of Retailing and Consumer Services. 2012;19(1):124-132. https:// doi.org/10.1016/j.jretconser.2011.11.001

22. Flavián C, Guinalíu M, Gurrea R. The role played by perceived usability, satisfaction and consumer trust on website loyalty. Inf Manage. 2006;43(1):114. https://doi.org/10.1016/j.im.2005.01.002

23. Brooke J. SUS - a quick and dirty usability scale. Usability Eval Industry. 1996;189(1996):194-200.

24. Sikdar P, Kumar A, Makkad M. Online banking adoption: A factor validation and satisfaction causation study in the context of Indian banking customers. Int J Bank Marketing. 2015;33(6):760-785. https://doi.org/10.1108/IJBM11-2014-0161
25. Szopiński TS. Factors affecting the adoption of online banking in Poland. J Bus Res. 2016;69(11):4763-4768. https://doi.org/10.1016/j. jbusres.2016.04.027

26. Brown I, Molla A. Determinants of internet and cell phone banking adoption in South Africa. The Journal of Internet Banking and Commerce. 2005;10(1):1-9

27. Mujinga M, Eloff MM, Kroeze JH. Online banking users' perceptions in South Africa: An exploratory empirical study. In: Proceedings of the IST-Africa Conference 2016; 2016 May 11-13; Durban, South Africa. Durban: IIMC; 2016. p. 1-7. https://doi.org/10.1109/istafrica.2016.7530617

28. Hanafizadeh P, Keating BW, Khedmatgozar HR. A systematic review of internet banking adoption. Telematics Inf. 2014;31(3):492-510. https://doi. org/10.1016/j.tele.2013.04.003

29. Montazemi AR, Qahri-Saremi H. Factors affecting adoption of online banking: A meta-analytic structural equation modeling study. Inf Manage. 2015;52(2):210-226. https://doi.org/10.1016/j.im.2014.11.002

30. Tassabehji R, Kamala MA. Evaluating biometrics for online banking: The case for usability. Int J Inf Manage. 2012;32(5):489-494. https://doi. org/10.1016/j.ijinfomgt.2012.07.001

31. Bhagavatula C, Ur B, lacovino K, Kywe SM, Cranor LF, Savvides M. Biometric authentication on iPhone and Android: Usability, perceptions, and influences on adoption. In: Proceedings of the USEC Conference; 2015 February 08 San Diego, CA, USA. Reston, VA: Internet Society; 2015. p. 1-10. https:// doi.org/10.14722/usec.2015.23003

32. Althobaiti MM, Mayhew P. Security and usability of authenticating process of online banking: User experience study. In: Proceedings of the 2014 International Carnahan Conference on Security Technology (ICCST); 2014 October 13-16; Rome, Italy. IEEE; 2014. p. 1-6. https://doi.org/10.1109/ CCST.2014.6986978

33. Turban E, King D, Lee JK, Liang T, Turban DC. Electronic commerce: A managerial and social networks perspective. London: Springer; 2015.

34. Gray DE. Doing research in the real world. 3rd ed. London: Sage Publications; 2014

35. Bangor A, Kortum P, Miller J. Determining what individual SUS scores mean Adding an adjective rating scale. J Usability Stud. 2009;4(3):114-123.

36. Bangor A, Kortum PT, Miller JT. An empirical evaluation of the system usability scale. Int J Hum Comput Interact. 2008;24(6):574-594. https://doi. org/10.1080/10447310802205776

37. Brooke J. SUS: A retrospective. J Usability Stud. 2013;8(2):29-40.

38. Hair Jr JF, Hult GTM, Ringle C, Sarstedt M. A primer on partial least squares structural equation modeling (PLS-SEM). 2nd ed. London: Sage Publications; 2016.

39. Arfaa J, Wang YK. A usability study on elder adults utilizing social networking sites. In: Proceedings of the International Conference of Design, User Experience, and Usability; 2014 June 22-27; Crete, Greece. Crete: Springer International Publishing; 2014. p. 50-61. https://doi.org/10.1007/978-3319-07626-3 5

40. Antonius R. Interpreting quantitative data with IBM SPSS statistics. 2nd ed. London: Sage Publications; 2013.

41. Pallant J. SPSS survival manual. 5th ed. Berkshire: McGraw-Hill Education; 2013

Appendix: System usability scale (SUS) measurement tool

\begin{tabular}{|c|c|c|c|c|c|}
\hline SUS items & $\begin{array}{c}\text { Strongly disagree } \\
1\end{array}$ & $\begin{array}{c}\text { Disagree } \\
2\end{array}$ & $\begin{array}{c}\text { Neutral } \\
3\end{array}$ & $\begin{array}{c}\text { Agree } \\
4\end{array}$ & $\begin{array}{c}\text { Strongly agree } \\
5\end{array}$ \\
\hline \multicolumn{6}{|l|}{ I think that I would like to use online banking more frequently } \\
\hline \multicolumn{6}{|l|}{ I find online banking unnecessarily complex } \\
\hline \multicolumn{6}{|l|}{ I thought online banking was easy to use } \\
\hline \multicolumn{6}{|l|}{ I need the support of a technical person to be able to use online banking } \\
\hline \multicolumn{6}{|l|}{ I found the various functions in online banking to be well integrated } \\
\hline \multicolumn{6}{|l|}{ I thought there was too much inconsistency in online banking } \\
\hline \multicolumn{6}{|l|}{ I would imagine that most people would learn to use online banking websites very quickly } \\
\hline \multicolumn{6}{|l|}{ I find online banking very difficult to use } \\
\hline \multicolumn{6}{|l|}{ I feel confident using online banking } \\
\hline I needed to learn a lot of things before I could get going with online banking & & & & & \\
\hline
\end{tabular}

